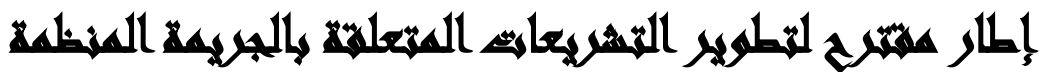

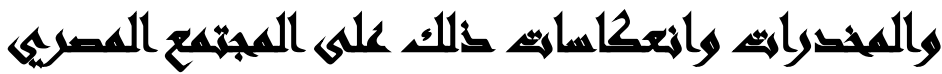

$[r \wedge]$

السيد عيد نايل(')- وائل فوزي عبد الباسط(؟) - منتصر عدلي عبد العزيز

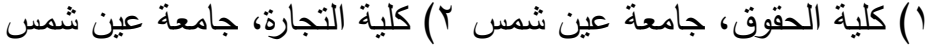

\section{المستصلص:}

إن الجريمة المنظمة والاتجار غير المشروع للمواد المخدرة أصبحت تتكل تهديداً مباشراً

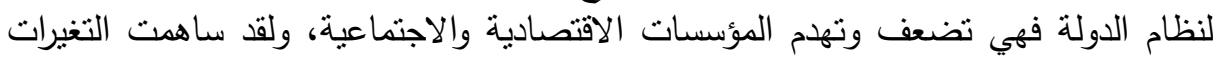

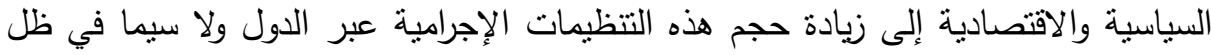

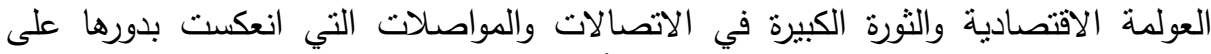

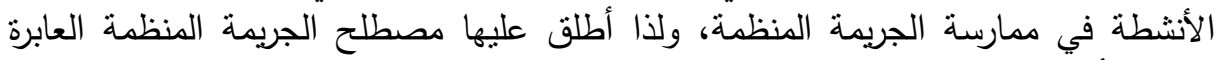

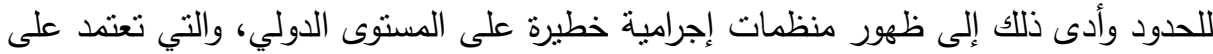
نظام وإستراتيجية التحالفات بهدف فرض إلى هيمنتها على الدول مما جعلها من أكبر التحديات التي تواجهه الدول سواء كانت متقدمة أو نامية.

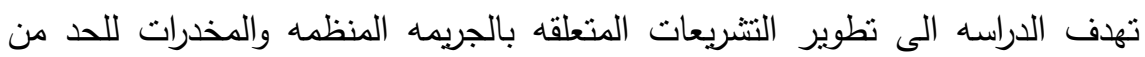

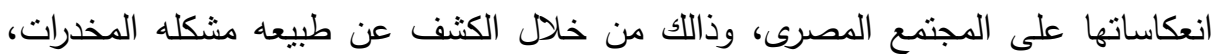
وتحديد مفهوم التشريعات والجريمه المنظمه، وتحديد أوجه القصور للتوصل التهل الى أهم التعديلات

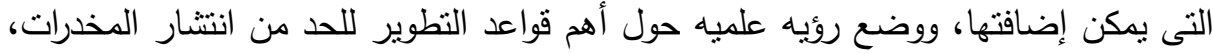

والانعكاسات المترتبه عليها.

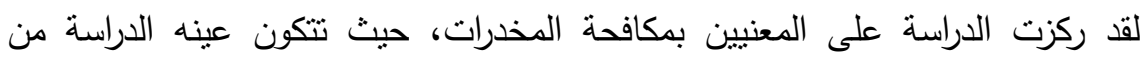

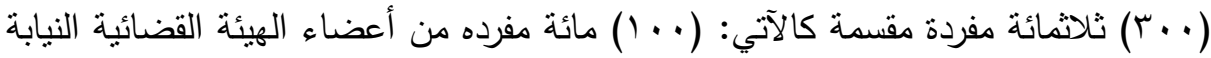

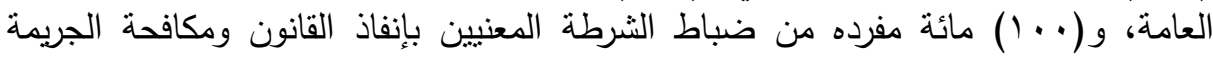

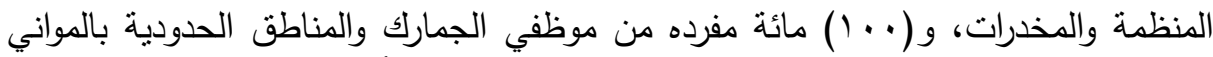
والمطارات. وتتتمي الدراسة إلى المنهج الوصفي الذي يعد من أنسب المناهج العندا العلمية لطبيعة

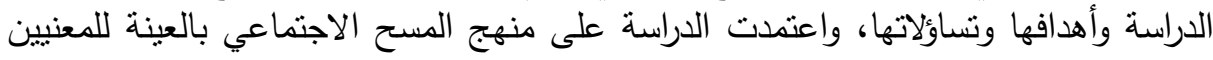

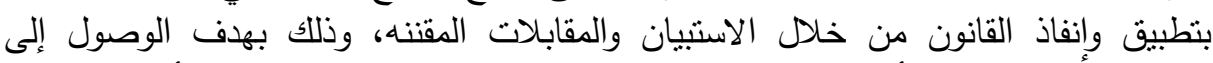

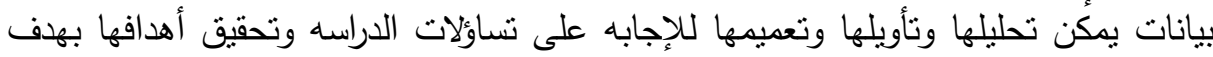

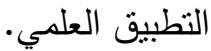

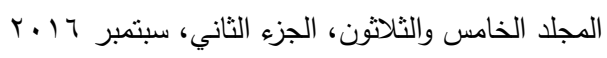




\section{xastl}

إن تفاقم ظاهرة انتشار الاتجار غير المشروع بالمخدرات في المجتمع المصري ترجع

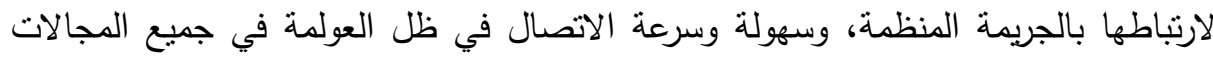
وزيادة درجات العنف وانتشار الفساد والرشوة والرغبة في الثراء غير المشروع. وأدى النطور

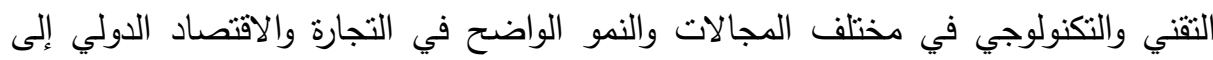
التوسع في مناطق التبادل الحر للتجارة العالمية وفتح أسواق جديدة، فانطلقت الجريمه من فن

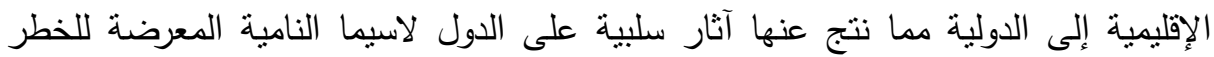
والاعتداء على أمنها واستقرارها ومصالحها. حيث أن الجريمة المنظمة نرتبط بممارسة أنشطة اقتصادية وتجارية، قد يعرض الاقتصاد للمخاطر نتيجة للممارسات غير القانونية والأنشطة غير المشروعة من الإتجار بالمخدرات. يؤكد الواقع الحالي زيادة حجم الجريمة المنظمة والإتجار غير المشروع، وهذا ما أكدته لهئه مختلف مؤتمرات الأمم المتحدة وآثارها بالغه الخطورة على المجتمعات النامية، واتفقت الدراسة الدية

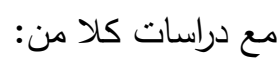
• اكساكال برباريز r . . rم "الجريمه المنظمه عبر الوطنيه وتجاره المخدرات".

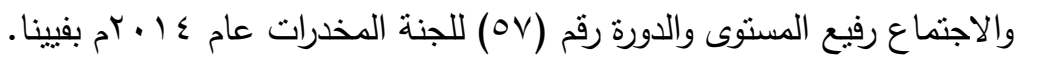
•دراسه سيد محمدين r...rم بعنوان "منهج مقترح لمواجهه الاسباب الاقتصاديه

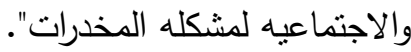

\section{x}

ما زالت تجارة المخدرات غير المشروعة تمنل تحدياً خطيراً في معظم بلدان العالم ولا

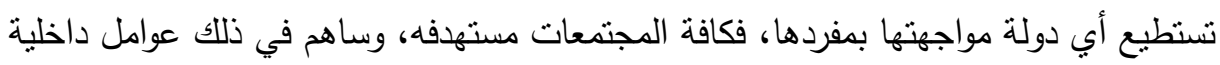
وخارجية مرنبطة بالعولمة والنظام الاقتصادي الجديد، وذللك لأن جلب وتهريب المخدرات يأتي من العديد من دول العالم، وتسيطر عليه جماعات إجرامية منظمة، مما أدى إلى انتشار المخدرات في المجتمع بهذه الصورة، ويؤكد أن هناك مشكلة تهدد المجتمع بل العاعل العالم كله، ومما

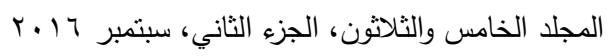


زاد المشكلة تعقيداً اتخاذ الاتجار غير المشروع بالمخدرات أحد أثنكال الجريمة المنظمة، وذلك نتيجة الظروف السياسية والاقتصادية التي تمر بها الدول، ولا سيما الدول النامية وهذه الظروف أدت إلى عدم قدرة الدول إلى مسايرة هذا التطور في الجريمة المنظمة، والأسلوب لهاب لهابه

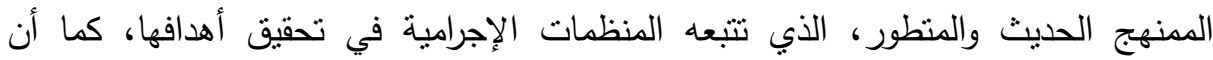
النطور الثنتي والتكنولوجي ساهم في انتشار أنواع من المخدرات حديثة بأنشكال وألوان جديدة التهات

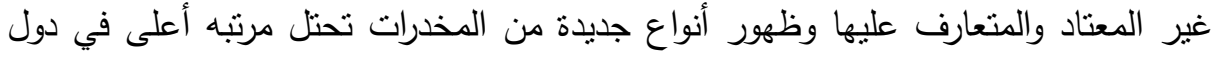
عن دول أخرى وذللك لاختلاف العادات والتقاليد المجتمعية في دولة عن أخراها، مما يؤكد أن أن

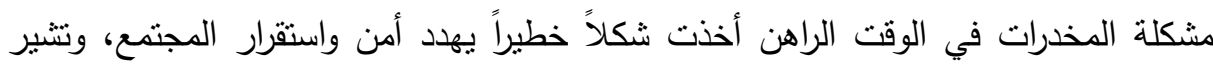
هذه الدراسات إلى ذلك.

- دراسة سمبر عبد الغنى، "مبادئ مكافحه المخدرات فى المكافحه واستراتيجيه المواجهة"،

$$
\text { . } 9
$$

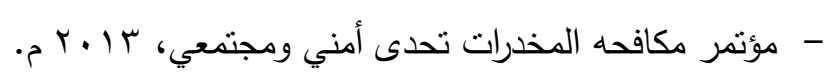

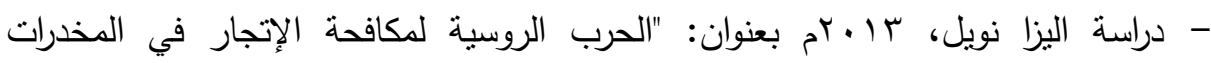

$$
\text { التحديات في تطوير القانون وقدرات الإنفاذ". }
$$

\section{تمساولاهي التصراسة}

من سرد مشكله المخدرات وارتباطها بالجريمة المنظمة، لأنها أحد أنشكالها الهامة، كان

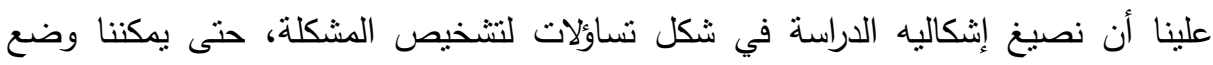

$$
\text { الحلول المناسبة للحد من انتشارها والتصدي لها. }
$$

التساؤل الرئيسي هو: "هل تنتح التشريعات الحالية إمكانية مواجهة الجريمة المنظمة والمخدرات وما إمكانية تطوير تلك التشريعات لتتكن من أداء دورها وما الانعكاسات المترتبة

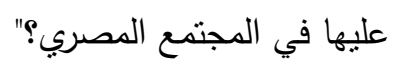

$$
\text { ويتفرع من التساؤل الرئيسي عده تساؤلات هي: }
$$

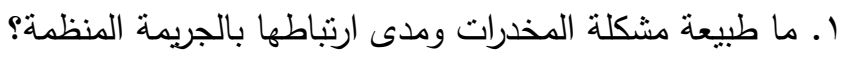

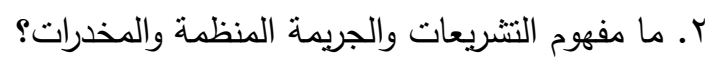

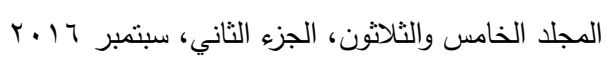




$$
\text { ץ. ما أوجه القصور في التشريعات الحالية؟ }
$$

ع. ما أهم التعديلات التي يمكن إضافتها لتطوير التشريعات الحالية ومدى ملاءمتها لتطوير

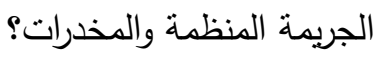

0. ما الروئة العلمية لتحديد أهم قواعد تطوير التشريعات المتعلقة بالجريمة المنظمة والمخدرات والانعكاسات المترتبة على انتشارها في المجتمع المصري وكيفية مواجتها؟

\section{أهمية القواسمة}

تتبلور أهمية الدراسة في تحديد مدى ارتباط الجريمة المنظمة بالمخدرات، والتعرف على طبيعة المشكلة، وتتاول الوضع الحالي للتشريعات الدولية والوطنية المتعلقة بالجريمة المنظمة والمخدرات والانعكاسات المترتبة عليها في المجتمع المصري، وكذا دراسة أهمية الاقتراح لتطور التشريعات الحالية لملاحقة النطور في أداء الجماعات القائمة على الجريمة المنظمة وخاصة المرتبطة بالمخدرات، وسد الثغرات أمام هذه الجماعات لعدم استغلالها في تحقيق أهدافها، وأهمية تدريب القائمين على مكافحة المخدرات على كيفية تطبيق القانون وإنفاذه للحد من هذه الظاهرة وانعكاسها على المجتمع المصري. لتهين حتى تتمكن الجهات العامله بالدوله فى مجال مكافحه المخدرات (الاداره العامه لمكافحه المخدرات - الهيئه القضائيه والنيابه العامه - مصلحه الجمارك - مكاتب المخدرات بمدريات الامن - قوات حرس الحدود) الاستفاده من تطوير النتريعات المتعلقه بالجريمه المنظمه والمخدرات لاداء دورها على الوجه الأمتل وتحقيق الردع للقائعين على الجريمه المنظمه هاته

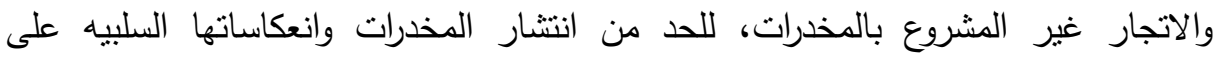
المجتمع المصرى.

\section{أهسا اهن التصوامد}

$$
\text { تتبلور أهداف الدراسة فيما يلي:- }
$$

ا ـ الكثف عن طبيعة مشكلة المخدرات ومدى ارتباطها بالجريمة المنظمة.

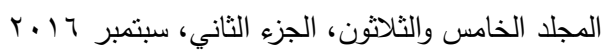


السيد عيد نايل وآخرون

r. تحديد مفهوم التشريعات والجريمة المنظمة والمخدرات.

r. تحديد أوجه القصور في التشريعات الحالية.

ع. التوصل إلى أهم التعديلات التي يمكن إضافتها لتطوير التتريعات الحالية ومدى ملاءمتها

للجريمة المنظمة والمخدرات.

ه. وضع رؤية علمية حول أهم قواعد نطوير التشريعات المتعلقة بالجريمة المنظمة والمخدرات

والاتعكاسات المترتبة على انتشارها في المجتمع المصري وكيفيه مواجنها.

\section{مهاهيمي التصواسم}

مفهوم الجريمة المنظمة: عرفتها اتفاقية الأمم المتحدة (باليرمو .... م م) بأنها: "تركز في عناصرها الأساسية على قيام جماعات إجرامية منظمة لارتكاب جريمة خطيرة من خلال

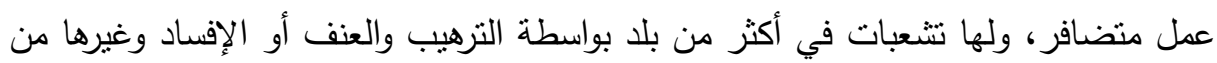

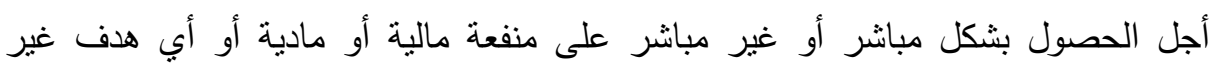
مشروع".

مفهوم المخدرات: تعريف المخدرات في الاتفاقية الدولية لمكافحة المخدرات عام 911 ام بأنه: "أبي مادة طبيعية كانت أو صناعية من المواد المدرجة في الجدول الأول والثاني من

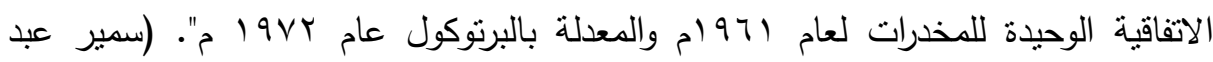

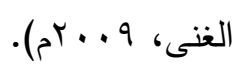

مفهوم القانون الدولي العام: عرفه صلاح الدين عامر سنه 990 ام بأنه: "مجموعة القواعد القانونية التي تحكم وتتظم المجتمع الدولي، وما يقوم في إطاره من علاقات بين أشخاصه القانونية".

مفهوم القانون الوطني: عرفه سمير عبد الغني 9.. بام بأنه: "ينصرف إلى تتظيم المجتمع الوطني الداخلي ووضع القواعد الخاصة التي تحكم العلاقات التي تنشأ في إطاره ويطبق في إقليم الدولة التي وضعته". 
مفهوم الاتفاقية الاولية: عرفتها محكمة النقض المصرية بأنها: "كل أثكال الاتفاق الدولي فيما بين دولتين أو أكثر إذ كان هذا الاتفاق في وثثقة واحدة أو أكثر وأياً كان نطاق

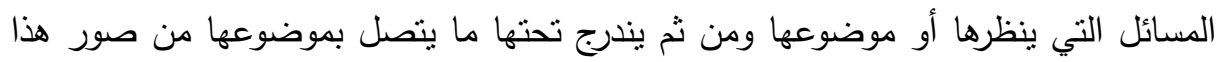

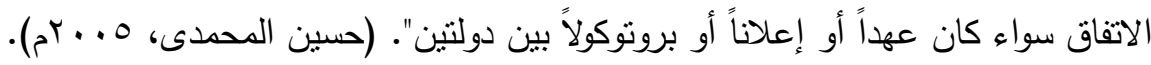

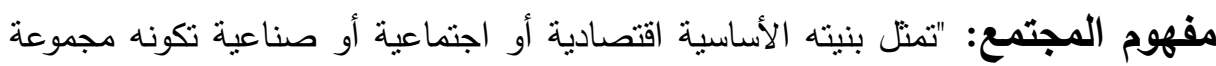
من الإفراد وقد يكون أعضاء المجتمع من مجموعات عرقية مختلفة". (مصطفى سويف،

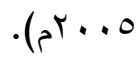

\section{الفواساوت الماوهية}

هناك العديد من الدراسات السابقة التي نتاولت الجريمة المنظمة والمخدرات وإنفاذ القانون نتناول منها:

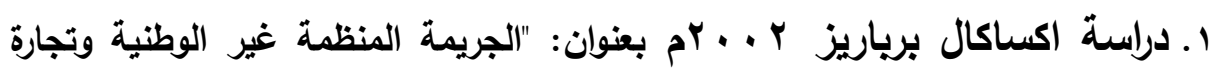
المخدرات" تتاولت الدراسة تحليل أنشطة الجريمة المنظمة للجماعات المنورطة في تجارة المخدرات ودراسة الجهود الوطنية والدولية للسبطرة على هذه الجماعات، واستهدفت الدراسة ماهية الجريمة المنظمة غير الوطنية والجماعات العاملة في مجال الأعمال الدولية للمخدرات، وطبيعة المشكلة من حيث صلتها بالجريمة المنظمة الدولية، وأظهرت الدراسة الدهة إلى ضرورة وجود جهود دولية لإنفاذ القانون التعاوني للتعامل مع الجريمة المنظمة وتجارة المخدرات ووجود شبكة لإنفاذ القانون الدولي لمواجهة التحديات من تهريب المخدرات، وأن الجهود المبذولة لمكافحة المخدرات والجريمة المنظمة ليست ناجحة إلى حد ما. r. دراسة براين فاليري ه ه . . بم بعنوان: "العوامل الاجتماعية والاقتصادية ونتائج

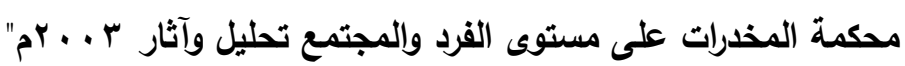

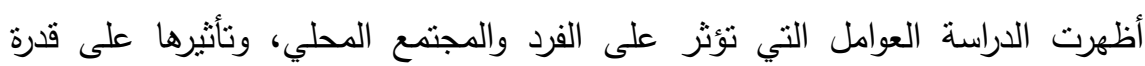
محاكم المخدرات لتعزيز الانتعانش وتقليل العودة للمخدرات. 
اعتمدت الدراسة وركزت علي التحليل متعدد المستويات، لبيان العلاقة بين نتائج البرنامج التي وضعته محكمة المخدرات والعودة للمخدرات، والتتبؤ بالغوص في المجتمع والعوامل

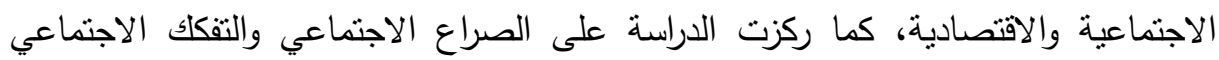

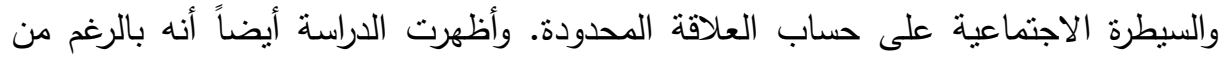
التعليم والدخل فقد حثت انتكاسة بالبرنامج وأن الدخل والتعليم مرتبطان بقوة الانتكاسة في

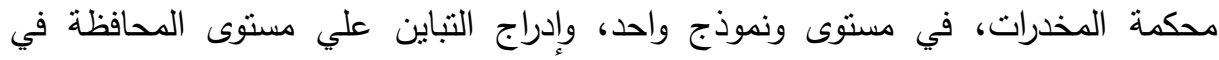
التحليلات، وأن النتائج تتفاوت حسب نوع وطريقة التقدير ومدى استقرار المجتمع.

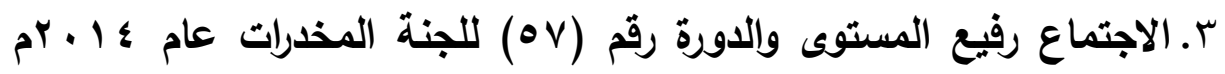
بفيينا: حيث هدف الاجتماع إلى اعتماد مشروع البيان الوزاري المشترك، المنبثق عن استعراض لجنة المخدرات عام ع ا ـ rم، لتنفيذ الدول الأعضاء الإعلان السياسي وخطة العمل بشأن التعاون الدولي لمواجهة مشكلة المخدرات العالمية.

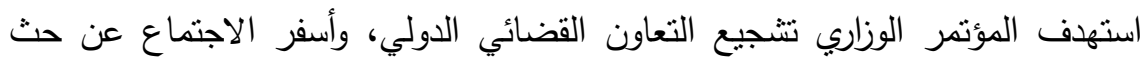

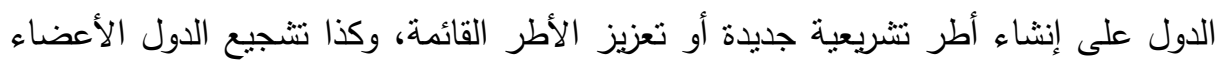

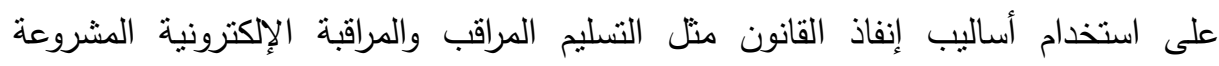
والعمليات المستمرة، بما ينوافق مع التشريعات الوطنية والقانون الدولي واحترام حقوق الإنسان

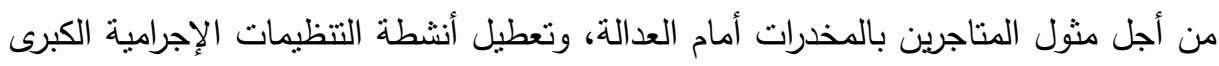

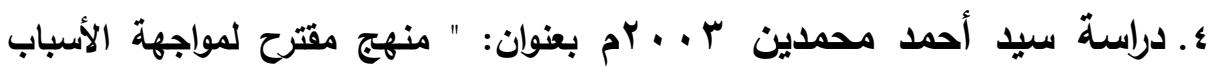
الاقتصادية والاجتماعية لمشكلة تعاطي المخدرات" تتاولت الدراسة الملامح العامة لمشكلة

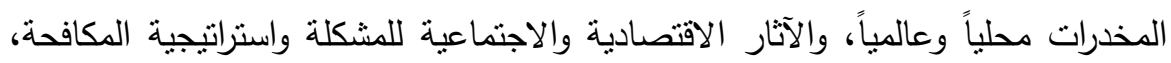
والنصور المستقبلي المقترح لمكافحة مشكلة انتشار المخدرات. أظهرت نتائج الدراسة وجود ولئه ثغرات قانونية، لا بد من معالجتها في ضوء التغيرات الاقتصادية والاجتماعية الحالية وإخفاق السياسات الحالية في القضاء على المشكلة أو الحد منها، و يرجع ذاللك إلى جهود المكافحة في مكافحة العرض دون خفض الطلب.

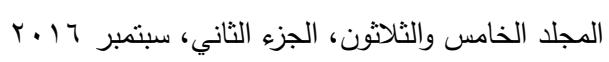




\section{الإلطار اللنظليمه}

نتتاول في هذا الإطار الجريمة المنظمة والمخدرات بين التشريع الدولي والداخلي، ونستعرض فيه التعريف بالقانون الدولي العام المعاصر للرقابة علي المخدرات وهو (مجموعة القواعد القانونية التي تتظم الوحدات الأساسية للجماعة الدولية، وتحكم العلاقات المنبادلة فيها، ولئن كانت قواعد القانون الدولي العام هي التي تحكم وتتظم المجتمع الدولي وما يقوم في لقدي إطاره من علاقات بين أشخاصه القانونية، فإن قواعد القانون الداخلي ينصرف إلي لتئي التظيم المجتمع الداخلي أو الوطني ووضع القواعد الخاصة التي تحكم العلاقات التي تتشأ في إطاره ويطبق في إقليم الدولة التي وضعته بينما نسري قواعد القانون الدولي علي الدجمع الدولي.

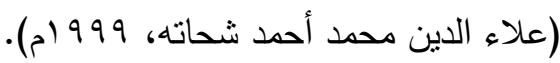
ثم تتاولنا أهم الاتفاقيات الدولية لمكافحه المخدرات، والتي اتقق عليها معظم دول العالم، المان، وفي عام اب9 ام شهد ميلاد أول اتفاقية للمخدرات وسميت بالاتفاقية الوحيدة للمخدرات

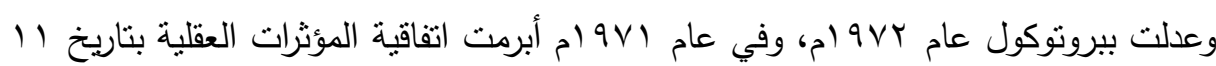

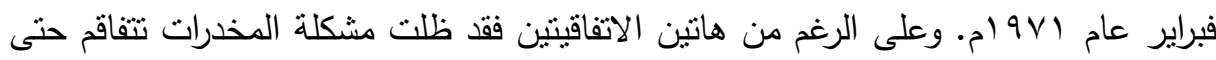

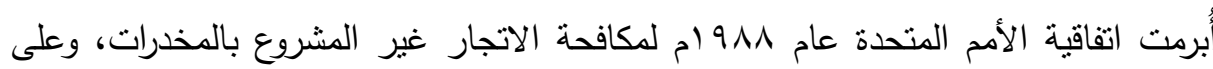

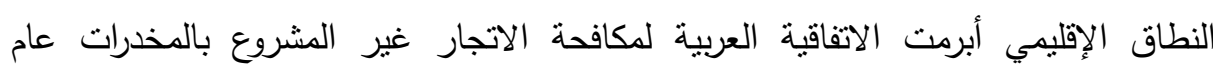

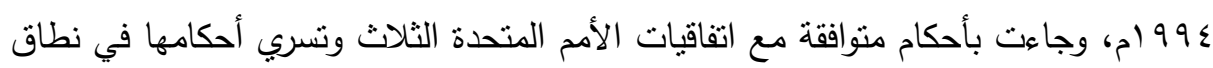

$$
\text { الدول العربية. (قاسم أسعد الردفانى، } 9 \text {. . بام). }
$$

ثم تتاولنا العلاقة بين القانون الدولي العام والقانون الداخلي والتي تبدو علاقة التجاوب

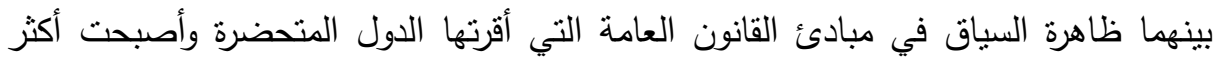
وضوحاً من خلال الإحاله والاستقبال وموقف الدساتير الوطنية، ثم الطبيعة القانونية للعلاقة

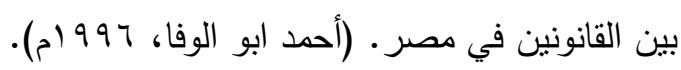

ثم تتاولنا في الإطار النظري، الجريمة المنظمة والمخدرات، التي اجتاحت كل دول العالم حتى أصبحت الجريمة المنظمة من أبرز التحديات التي تواجه المجتمع الدولي، كجريمة عابرة

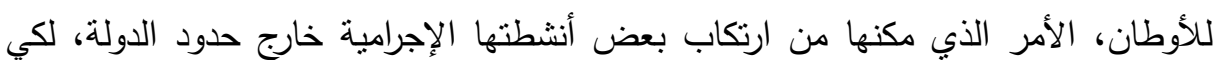


يعبث بأمنها واستقرارها، وبذلت الأمم المتحدة جهوداً مضنية، لمحاربة هذا الخطر الجديد الذي

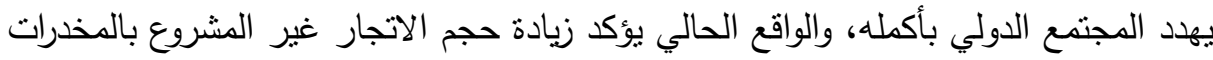
لارتباطه بالجريمة المنظمة، وهذا ما أكدته مختلف المؤتمرات والندوات التي تعقدها الأمم المتحدة بشأن المخدرات، لذا لزم الأمر فهم الجريمة المنظمة والإحاطة بكافة جوانبها وذللك بتعريفها بقصد الوصول إلي تحديد الصفات الأساسية المميزة لها، بغية الوصول إلي معرفة

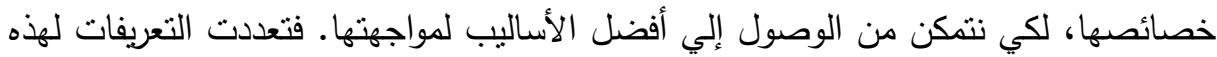
الجريمة فعرفتها الأمم المتحدة في (باليرمو) عام ل .. بم (بأنها تركزت عناصرها الأساسية على قيام جماعات إجرامية منظمة، بارتكاب جريمة خطيرة، من خلال عمل متضافر ، ولها

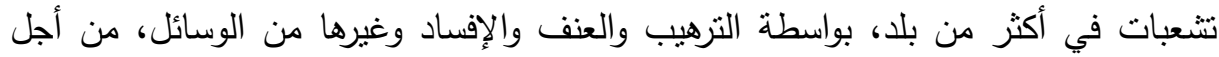

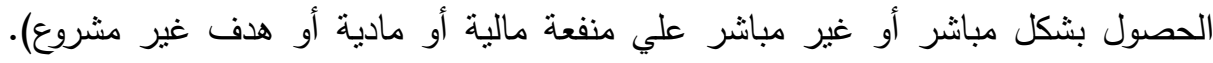

$$
\text { (سمير عبد الغنى، } 0 \text {. - بام). }
$$

تتاولنا في الإطار النظري التشكيلات العصابية والتي تحكمها التكتلات الاقتصادية

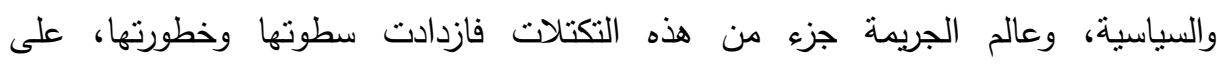
المجتمعات كافه ورغم أهية هذا الموضوع، فقد أهمله الفقه الجنائي وتتاساه حتى يمكننا أن نطلق عليه النسيان المدني ولعلنا بهذا نسلط الضوء علي هذه المنطقة في قانون العقوبات التي ظلت لسنوات دون رؤية واضحة ويحتل موضوع التثكيلات العصابية أهمية بالغه من هن فئن

$$
\text { الناحية النظرية والعلمية. (هدى حامد قشقوش، } 7 \text {. . ب م). }
$$

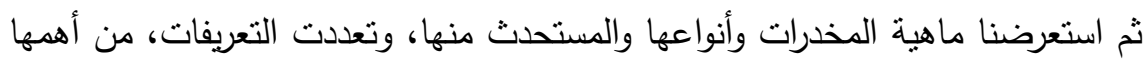

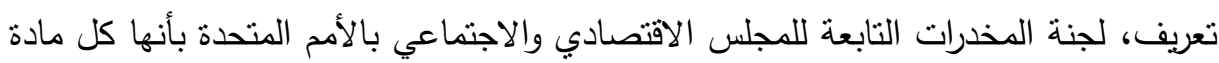

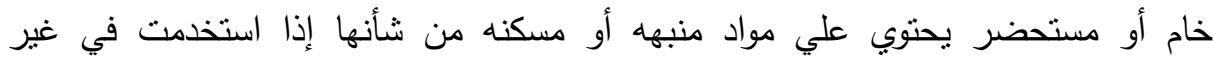

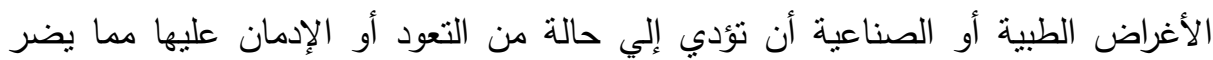

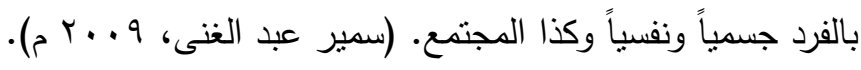

أنواع المخدرات عديدة، تم تصنيفها وفق عدة معايير، أهمها المعيار الدولي وتم تصنيفها إلي: ا. مواد مخدرة وتتثل المواد المدرجة علي الجداول الأربعة الملحقة بالاتفاقية الوحيدة

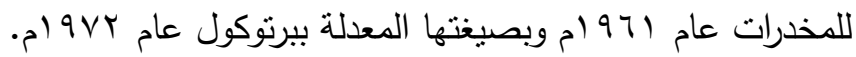

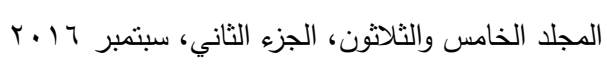


r. مؤثرات عقلية وتتشل المواد المدرجة باتفاقية المؤثرات العقلية عام الو9 ام. r. السلائف الكيماوية وهي من المواد التي تنتخدم في صنع المواد المخدرة وهي ليست مخدرة في حد ذاتها وهي مدرجه باتفاقية الاتجار غير المشروع عام 9 ام. (المجلس القومى

$$
\begin{aligned}
& \text { لمكافحة وعلاج الادمان، ... . بم). } \\
& \text { المخدرات المستحدثة: }
\end{aligned}
$$

الحشيش الصناعي وهي مواد مخلقه صناعية تحفز الجهاز العصبي وتم تصنيعها من الأعشاب الطبيعية وخلطها برزاز ومواد كيماوية وعندما يتم تعاطيها تعطي تأثثر مشابه لتأثير الحشيش الطبيعي وسمي بالفودو . (2012،Melaine Haiken).

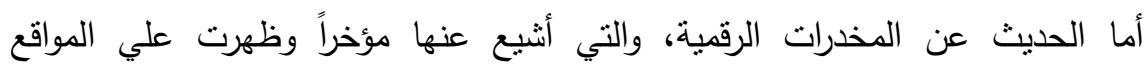
الاككترونية وقيل (بأنها تخدر العقل وتؤثز علي الجهاز العصبي المركزي وتعطي إحساساً

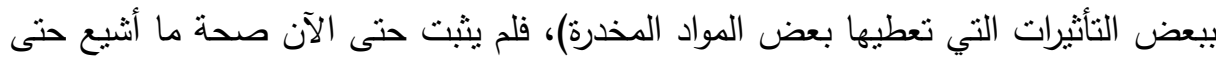

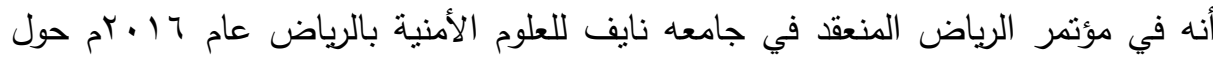

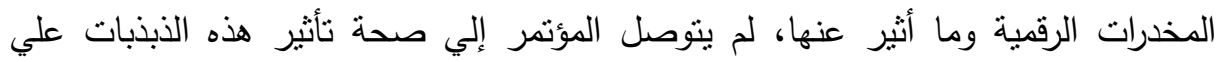

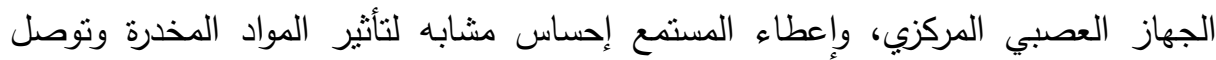

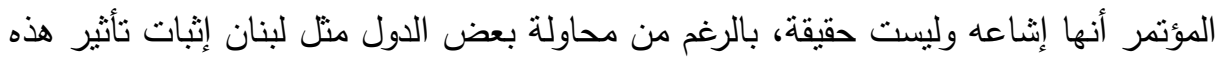
الذبذبات لنفس تأثير المواد المخدرة علي الجهاز العصبي المركزي. (مؤتمر المخدرات الرقميه

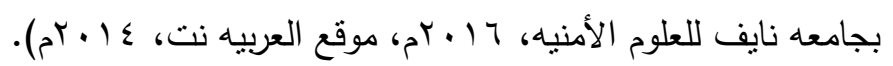


تتاولت الدراسة حجم انتشار ظاهرة المخدرات في مصر من خلال البيانات والإحصائيات الصادرة من وزارة الداخلية - الإدارة العامة لمكافحة المخدرات، لأعداد المتهمين وعدد القضايا المضبوطة في جريمة المخدرات، وكذاللك الكميات المضبوطة من المواد المخدرة ومتوسط الأسعار لكل من المواد المخدرة، وأحكام الإدانه وأحكام الحفظ والبراءة وذللك خلال عشرة

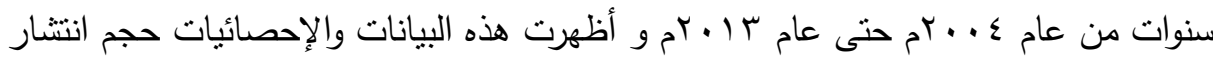
هذه الظاهرة في المجتمع المصري مدي تأثيرها اقتصادياً واجتماعياً علي الفرد والمجتمع.

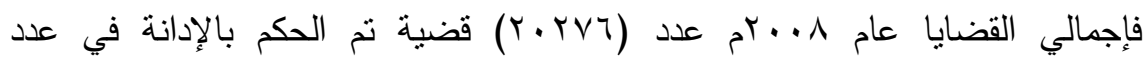

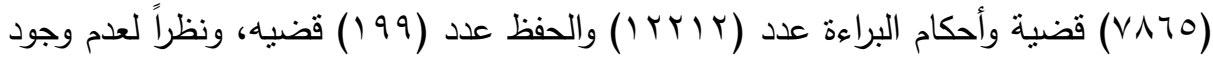

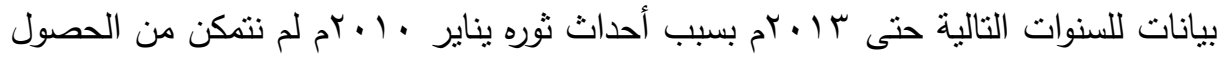
على بيانات موتقه لأحكام الإدانه والحفظ والبراءة، حتى يمكن إضافتها بالدراسة. (تقارير وزارة

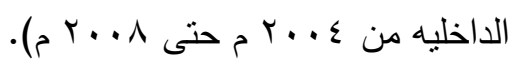
ثم تتاولنا الانعكاسات الاقتصاديه في الإطار النظري، حيث جاءت بـثاء بيانات الأمم المتحدة

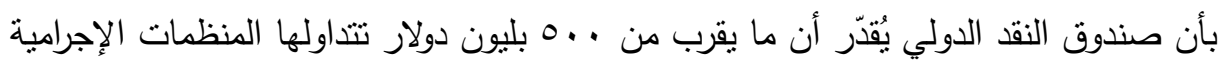

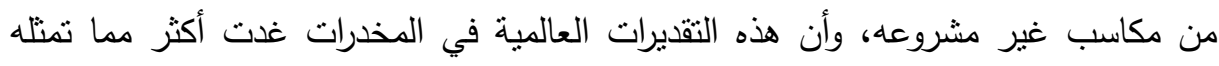
التجارة العالمية في النفط سنوياً وتقدر الأموال المستمدة من المخدرات والجريمة المنظمة بصفه

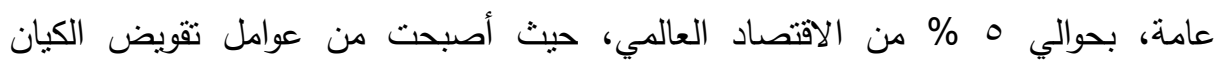
الاقتصادي للاول، ففي الدول النامية ما بين • 1\% - 10 \% \% من ميزانية الدول تتفق لمواجهة

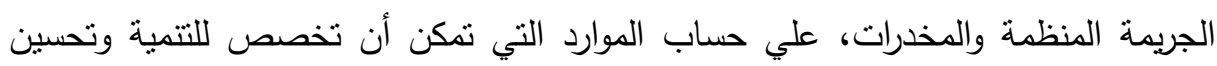
نوعية الحياة، والجدير بالذكر أنه لا نوجد إحصائيات أو بيانات يعتمد عليها في تقدير تكلفة الجريمة في الوطن العربي. (تقرير الامم المتحده المعني بالمخدرات، و ج. . بم).

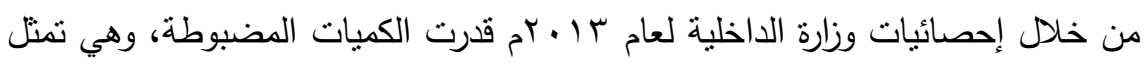
• 1\% من الكميات المتداولة في السوق المصري، وبحسابها حسب متوسط سعر المستهلك

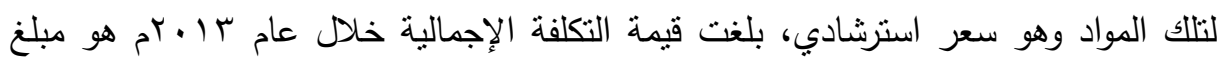

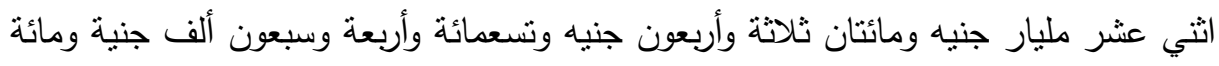

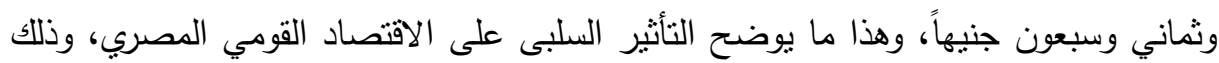

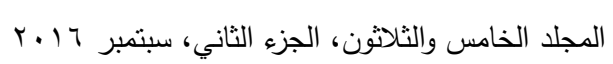


بخلاف العقاقير المؤثرة علي الحالة النفسية والعصبية المدرجة علي الجدول رقم (؟) من قانون المخدرات وتكاليف المكافحة وتأثثر المخدرات علي الإتتاج والصحة العامة وزيادة حالات

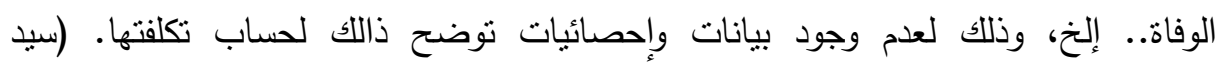

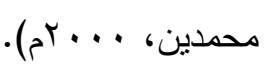
جاء بيان المركز القومى للتعبئة والإحصاء بأن الخسائر الاقتصادية على الاقتصاد

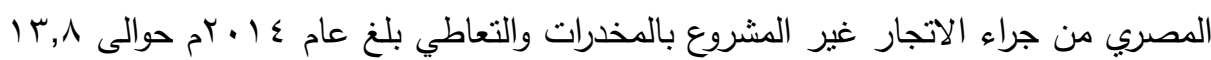

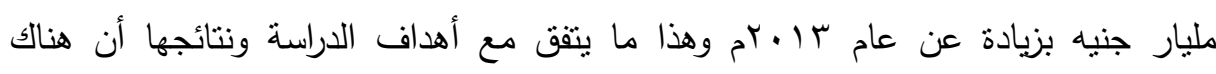

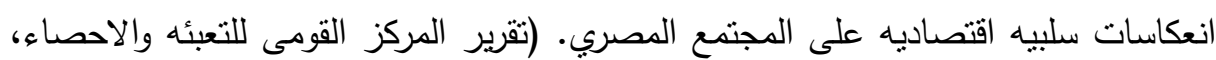
$\left.\cdot()^{2} \cdot\right) \leq$

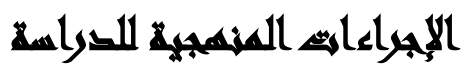

نوع الدراسةة: تعتبر هذه الدراسة من الدراسات الوصفية التحليلية لأنها أنسب أنواع الدراسات الملائمة لطبيعة موضوع الدراسة. منهج الاراسة: المنهج المستخدم هو المنهج الوصفي من خلال استخدام المسح الاجتماعي بالعينة للمعنيين بتطبيق القانون وإنفاذه.

$$
\text { أدوات الاراسةة: تعتمد الدراسة على الأدوات الآتية: }
$$

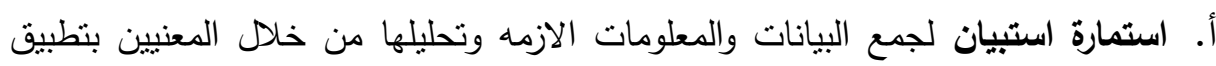
القانون وانفاذه وذاللك للاجابه على تساؤلات الدراسه وتحقيق اهدافها، ويتتاول الاستبيان

$$
\text { ثلاثة أبعاد، هم: }
$$

- البعد الأول: النشريعى فى عدد (ب0) خمس وثلاثثون سؤال تتاول محور الجوانب التشريعيه.

- البعد الثانحي: الاقتصادى فى عدد ( • (1) عشرة أسئله تتاولت محور الجوانب الاقتصاديه. - البعد الثالث: الاجتماعى فى عدد (9) تسعة أسئله تتاولت محور الجوانب الاجتماعيه. 
ب. المقابلات المقتنه مع القادة والمسئولين في الأجهزة المعنية بموضوع الدراسة لمعرفه الثغرات التنريعيه وكيفيه تعديلها وتطويرها لمواكبة النظور فى الجريمه المنظمه

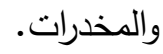

ج. اختبار الصدق والثبات: استخدم الباحث معادلة ألفا كرونباخ Alpha Cronbachs لاختبار ثبات الاستبيان، ومعامل ارتباط بيرسون لحساب صدق الاتساق الداخلى لأبعاد

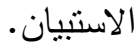

- اختبار الثبات: للتحقق من ثبات الاستبيان استخدم الباحث معادلة ألفا كرونباخ (Alpha Cronbach) الأولية. ويوضح الجدول التالي معاملات الثبات الناتجة باستخدام هذه المعادلة. جدول( (1): ثبات العبارات لأبعاد الاستنيان (ن=.0.0)

\begin{tabular}{|c|c|c|}
\hline قيمة ألفا & عدد العبارات & أبعاد المقياس \\
\hline י & ro & الجانب التشريعى \\
\hline$\cdot, \vee \vee 74$ & 9 & الجانب الاقتصادى \\
\hline ., VOr & 1. & الجانب الاجتماعي \\
\hline
\end{tabular}

يتضح من الجدول السابق أن قيم معاملات الثبات جميعها قيم مرتفعة حيث بلغت قيم

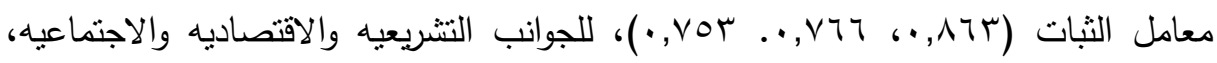

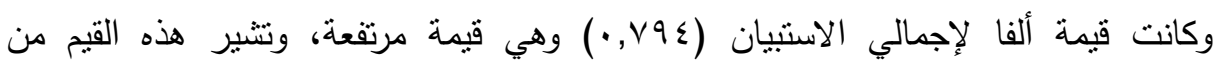
معاملات الثبات إلى صلاحية الاسنبيان للنطبيق وإمكانية الاعتماد على نتائجه والوثوق بهان.

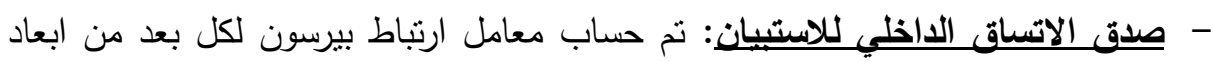

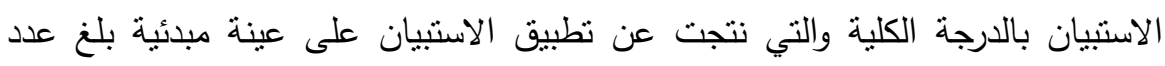

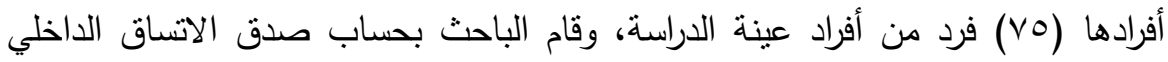
ومعامل الارتباط المصحح كما هو مبين بالجدول النالى:- 


\begin{tabular}{|c|c|c|c|}
\hline معامل الارتباط المصحح & إجمالي & ستبيان & أبعاد \\
\hline \multirow{2}{*}{$\cdot, 9 \leq$} & $(* *) \cdot, \wedge \wedge 1$ & معامل ارتباط بيرسون & \multirow{2}{*}{ الجانب التشريعى } \\
\hline & $\cdot, \ldots 1$ & الدلالة المعنوية & \\
\hline \multirow{2}{*}{$\cdot, \mathrm{VV}$} & $(* *) \cdot, 7 T \leq$ & معامل ارتباط بيرسون & \multirow{2}{*}{ الجانب الاقتصادى } \\
\hline & $\cdot, \ldots 1$ & الدلالة المعنوية & \\
\hline \multirow{2}{*}{$\cdot, \mathrm{VO}$} & $\cdot, 710$ & معامل ارتباط بيرسون & \multirow{2}{*}{ الجانب الاجتماعى } \\
\hline & $\cdot, \cdots 1$ & الدلالة المعنوية & \\
\hline
\end{tabular}

من جدول صدق الاتساق الداخلي السابق للاستبيان، نجد أن معامل ارتباط أبعاد

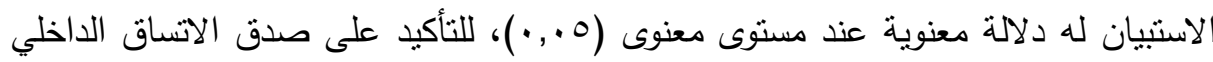

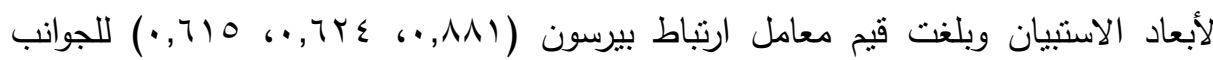

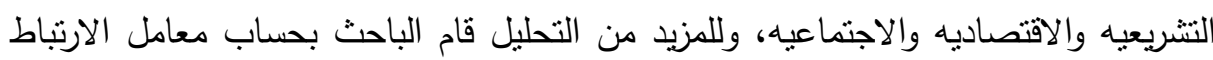

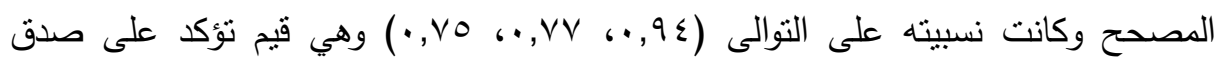

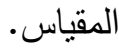
- المعالجة الإحصائية: نم تفريغ البيانات عن طريق البرنامج الإحصائي المعروف وهو

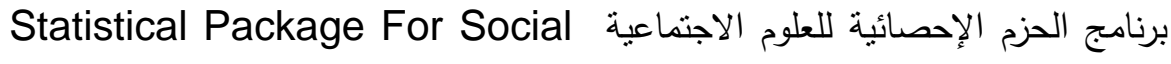
Sciences

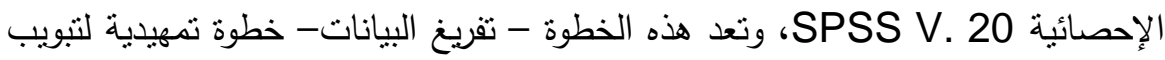
البيانات، لإجراء الإحصاءات الوصفية للبيانات وجدولتها في صورة جداول تكرارية (التكرار

$$
\text { والنسبة المئوية) لأسئلة استمارات الاستنيان. }
$$

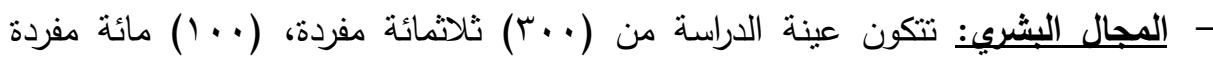

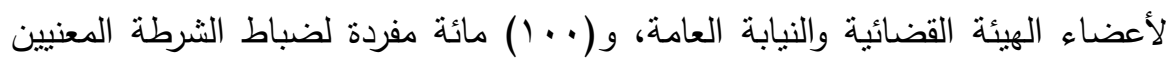

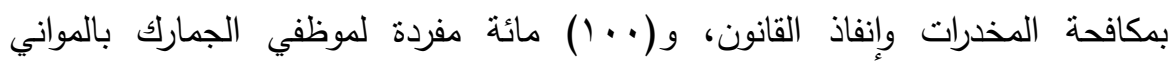
والمطارات 
أسباب اختيار العينة: تعتبر هذه العينة هي المنوط بها نطبيق وإنفاذ القانون في مجال مكافحة المخدرات، وانتماء الباحث إلى رجال مكافحة المخدرات بوزارة الداخلية. - المجال الجغرافي: تم اختيار أغلب محافظات الجمهورية لتطبيق الاستبيان. أسباب اختيار المجال الجغرافي: بالرغم من الصعوبة التي واجهه الباحث في تطبيق الاستمارة

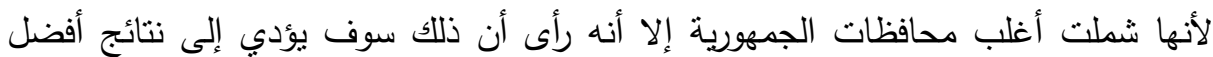

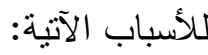
أ. لبيان أوجه القصور في التشريعات الحالية وعدم ملاءمتها للجريمة المنظمة والاتجار غير

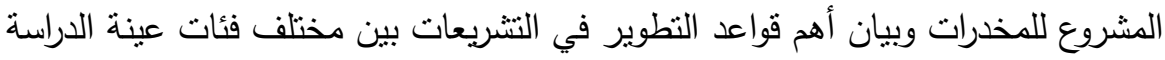

$$
\text { في أغلب محافظات الجمهورية. }
$$

ب.ليشمل التطبيق عدداً كبيراً من المحافظات لبيان طبيعة مشكلة الدراسة وعما إذا كانت المشكلة تواجه نطافًا معينًا من جمهورية مصر العربية أم المجتمع المصري كله لهن. ج. للوصول إلى نتائج أفضل تقيد الدراسة.

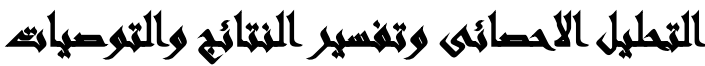

جدول(ץ): توزيع عينة الدراسة طبقاً لوجود علاقة بين التجارة الغير مشروعة للمخدرات والجريمة المنتظمة

\begin{tabular}{|c|c|c|c|c|c|c|c|c|}
\hline \multicolumn{2}{|c|}{ الإجمالي } & \multicolumn{2}{|c|}{ رجال الشرطة } & \multicolumn{2}{|c|}{ موظفي الجمارك } & \multicolumn{2}{|c|}{ القضاة والنيابة } & \multirow{2}{*}{ الاستجابة } \\
\hline$\%$ & S & $\%$ & S & S & S & $\%$ & ك & \\
\hline $97, r$ & 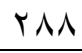 & 91,1 & 91 & $9 r, 0$ & 94 & $9 \wedge, 1$ & 91 & موافق \\
\hline$r, 1$ & 1. & 1,9 & r & $V, 0$ & $\Lambda$ & $\cdot, \cdot$ & . & غير موافق \\
\hline$\cdot, 7$ & $r$ & $\cdot, \cdot$ & - & $\cdot, \cdot$ & - & 1,9 & $r$ & محايد \\
\hline $1 \ldots$ & r.. & $1 \ldots$ & $1 \ldots$ & $1 \ldots$ & $1 \ldots$ & $1 \ldots$ & $1 \ldots$ & الإجمالي \\
\hline
\end{tabular}

توصلت الدراسة من خلال الجدول الاحصائى للبيانات الواردة بجدول رقم (r) والمتعلق بمدى وجود علاقة بين التجارة غير المشروعة للمخدرات والجريمة المنظمة، حيث تحنل الموافقة على وجود علاقة بين التجارة الغير مشروعه للمخدرات والجريمة المنظمة من خلا

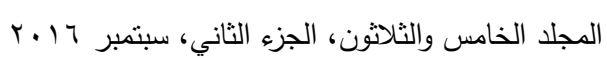


بيانات الجدول، أن آراء العينة التي نم التطبيق عليها وعددها (...r) مفرده أن نسبة

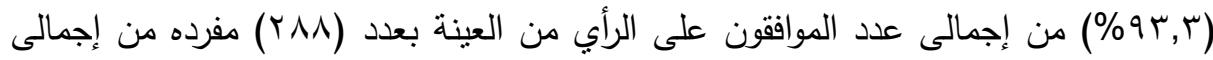

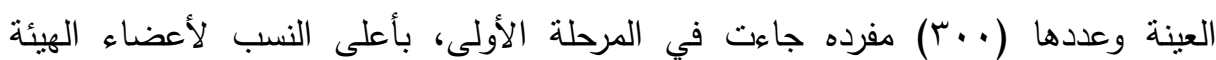

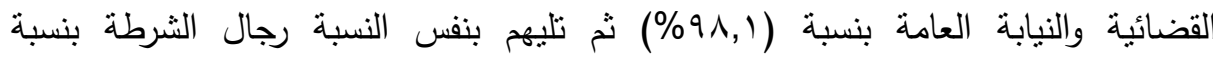

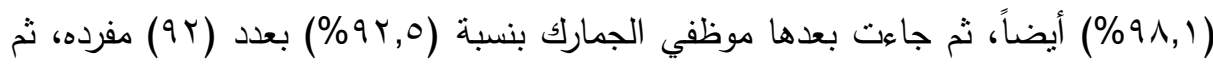

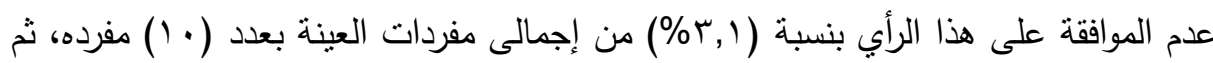

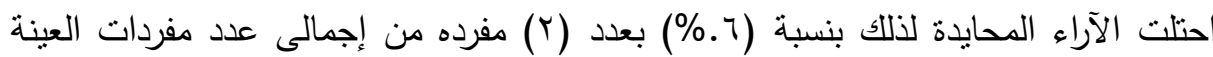
ومما يدل ذلك على التأكيد، أن تجارة المخدرات غير المشروعة تعد جريمة من الجرائم المنظمة، والتي وافق عليها الغالبية العظمى من أفراد العينة لكونها تهدد أمن وسلامة أنها

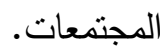

وهذه النتيجة تتفق مع دراسة اكساكال برباريز عام r +..rم بعنوان (الجريمة المنظمة

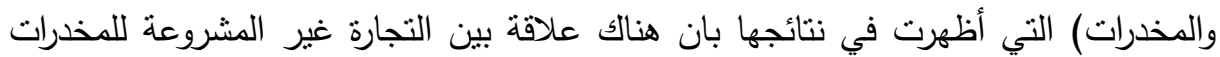
والجريمة المنظمة، ولابد من تضافر الجهود الدولية للتعامل مع الجريمة المنظمة وتجارة

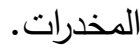

كما اتفقت الاحصائيه السابقة مع أهداف دراسة ريان وكينيث جيمس بعنوان (الاستخبارات الجنائية في الاتحاد الاوربى- تقيم الكفاءة العملية للتعاون والتتسيق) عام لهان

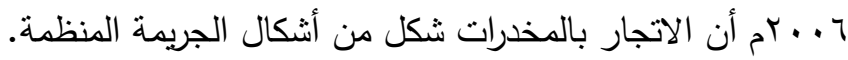

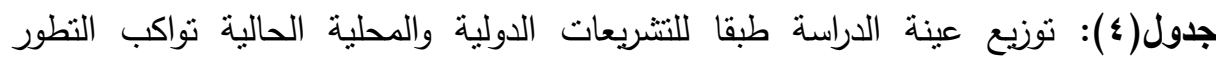
الملحوظ في الجريمة والمخدرات

\begin{tabular}{|c|c|c|c|c|c|c|c|c|}
\hline \multicolumn{2}{|c|}{ الإجمالي } & \multicolumn{2}{|c|}{ رجال الشرطة } & \multicolumn{2}{|c|}{ موظفي الجمارك } & \multicolumn{2}{|c|}{ قضاة ونيابة } & \multirow{2}{*}{ الاستجابة } \\
\hline$\%$ & ك & $\%$ & ك & 5 & 5 & $\%$ & S & \\
\hline $1 \pi, \lambda$ & $\varepsilon$. & $\Gamma, v$ & $\varepsilon$ & $r Y, T$ & Tr & 10,1 & $1 \varepsilon$ & موافق \\
\hline$V 7,9$ & TMY & $9 r, 7$ & $9 Y$ & $T \varepsilon, Y$ & $7 \varepsilon$ & $V Y, T$ & VI & غير موافق \\
\hline $9, \varepsilon$ & r^ & $\Gamma, v$ & $\varepsilon$ & $1 T, r$ & $1 \leq$ & $11, \pi$ & 1. & محايد \\
\hline $1 \ldots$ & $r \ldots$ & $1 \ldots$ & $1 \ldots$ & $1 \ldots$ & $1 \ldots$ & $1 \ldots$ & $1 \ldots$ & الإجمالى \\
\hline
\end{tabular}


من البيانات الموضحة في الجدول رقم (ع) والمتعلقة بمواكبة التشريعات الدولية والمحلية لللطور الملحوظ للجريمة المنظمة والمخدرات، حيث احتلت المرنبة الأولى في عدم الموافقة

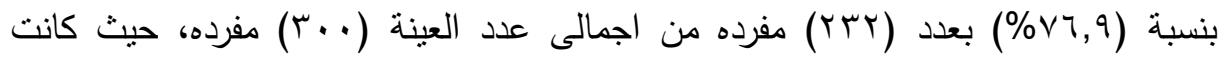

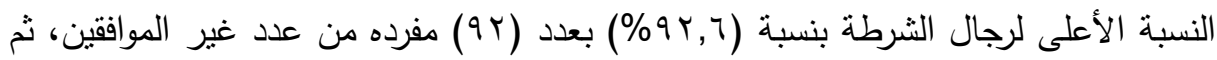

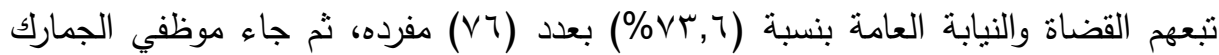

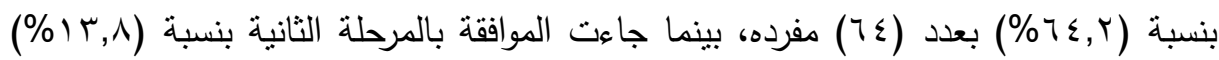
بعدد (••) مفرده من إجمالى عدد العينة ككل، ثم جاءت الآراء المحايدة في المرحلة الثالثة بنسبة (₹, (9) وعدد (Y^) مفرده من اجمالى عدد العينة ككل مما يدل ذللك على إجماع غالبية الآراء على عدم مواكبة التشريعات الدولية والمحلية لهذه الجرائم، ولابد من تطوير هذه التشريعات لمواكبه التطور في الجريمة المنظمة والمخدرات. تتفق هذه النتيجة مع دراسة اليزا نويل عام با ــام بعنوان (الحرب الروسية لمكافحه

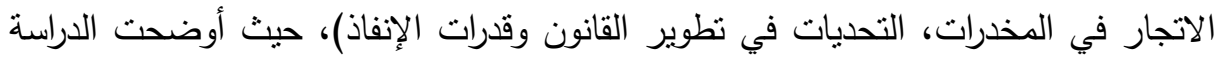
ضرورة التركيز على جهود المكافحة للاتجار غير المشروع بالمخدرات وتطوير القانون لمواجهه التحديات. واتفقت أيضاً نتيجة الدراسة الحالية المبينة في الجدول السابق مع (الاجتماع رفيع

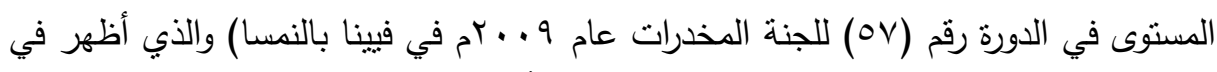
نتائجه وتوصياته، بحث الدول الأعضاء على إنثاء أُطر تشريعيه جديدة أو تعزيزها، وتحسين التعاون القضائي. جدول(ه): نوزيع عينة الدراسة طبقا للإجراءات الحالية لقضايا المخدرات

\begin{tabular}{|c|c|c|c|c|c|c|c|c|}
\hline \multicolumn{2}{|c|}{ الإجمالي } & \multicolumn{2}{|c|}{ رجال الشرطة } & \multicolumn{2}{|c|}{ موظفي الجمارك } & \multicolumn{2}{|c|}{ قضاة ونيابة } & \multirow{2}{*}{ الاستجابة } \\
\hline$\%$ & ك5 & $\%$ & ك5 & ك & 5 & $\%$ & ك5 & \\
\hline $9, \varepsilon$ & rA & 0,7 & 7 & $10, \varepsilon$ & $1 \varepsilon$ & $v, 0$ & $\wedge$ & موافق \\
\hline$\Lambda \uparrow, r$ & YOA & $\wedge \wedge, \wedge$ & $\Lambda \Lambda$ & $\Lambda \cdot, \wedge$ & $\Lambda$. & $\wedge \wedge, \vee$ & 9. & غير موافق \\
\hline$\varepsilon, \varepsilon$ & ir & 0,7 & 7 & $r, \Lambda$ & $\varepsilon$ & $r, \Lambda$ & $r$ & محايد \\
\hline $1 \ldots$ & r.. & $1 \ldots$ & $1 \ldots$ & $1 \ldots$ & $1 \ldots$ & $1 \ldots$ & $1 \ldots$ & الإجمالي \\
\hline
\end{tabular}


يتضح من البيانات الواردة في الجدول رقم (0) والتي تتعلق بالإجراءات الجنائية الحالية لقضايا المخدرات تحقق السرعة في الأحكام لتحقيق الردع والحد من انتشار المخدرات حيث جاءت البيانات توضح عدم الموافقة على عدم وجود إجراءات من شأنها تحقق السرعة في البت في قضايا المخدرات بنسبة (r,Y^\%) من إجمالى العينة بعدد (YO^) مفرده من الاجمالى العام، حيث جاءت نسبة رجال الثرطة (^^^/^) بعدد (^^) مفرده، ثم رجال القضاء والنيابة العامة بنسبة (\%^,v\%) بعدد (•q) مفرده ثم موظفي الجمارك بنسبة

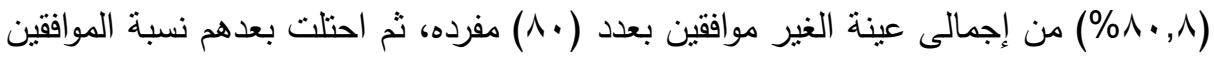

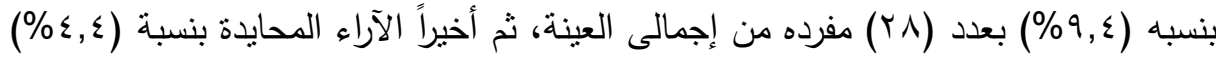
بعدد (r I) مفرده من الاجمالى العام، مما يدل على أن قانون الإجراءات الحالي يتسم بالبطئ، ولا يحقق السرعة في البت في القضايا ولا يحقق الحد من انتشار المخدرات. وتتفق نتيجة الجدول السابق مع دراسة اكساكال برباريز بعنوان (الجريمة المنظمة

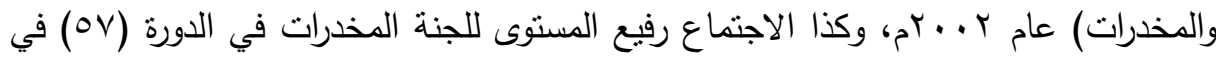
فيينا، النمسا عام 9. . rم، والذي حث بتشجيع الدول الأعضاء بتحسين التعاون القضائي على الأصعده الوطنية والإقليميه والدولية، بغية تفكيك مجموعات الجريمة المنظمة الضالعة في الاتجار بالمخدرات واتخاذ التدابير اللازمة، لمنع مرتكبي هذه الجريمة من تحقيق أهدافها،

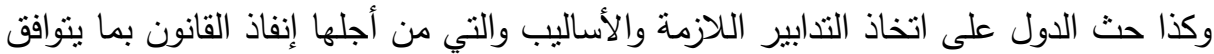

$$
\text { مع تشريعاتها. }
$$

جدول(؟): توزيع عينة الدراسة طبقا لحاجه قانون الجمارك للنطوير لسد الثغرات

\begin{tabular}{|c|c|c|c|c|c|c|c|c|}
\hline \multicolumn{2}{|c|}{ الإجمالي } & \multicolumn{2}{|c|}{ رجال الثرطة } & \multicolumn{2}{|c|}{ موظفي الجمارك } & \multicolumn{2}{|c|}{ قضاة ونيابة } & \multirow{2}{*}{ الاستجابة } \\
\hline$\%$ & ك & $\%$ & ك & 5 & ك5 & $\%$ & ك5 & \\
\hline $9 r, v$ & YAT & $1 \ldots$ & $1 \ldots$ & $\wedge \wedge, \vee$ & 9. & $97, r$ & 97 & موافق \\
\hline$\varepsilon, \varepsilon$ & 1. & $\cdot, \cdot$ & · & $V, 0$ & $\Lambda$ & 1,9 & $r$ & غير موافق \\
\hline 1,9 & $\varepsilon$ & $\cdot, \cdot$ & . & $\Gamma, \wedge$ & $r$ & 1,9 & r & محايد \\
\hline $1 \ldots$ & r... & $1 \ldots$ & $1 \ldots$ & $1 \ldots$ & $1 \ldots$ & $1 \ldots$ & $1 \ldots$ & الإجمالي \\
\hline
\end{tabular}

يتضح من بيانات الجدول رقم (7) والمتعلق بحاجه قانون الجمارك للتطوير لمواكبة الأساليب المنطورة للجماعات المنظمة القائمة على الاتجار غير المشروع بالمخدرات وسد لإنا 644

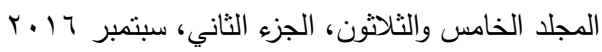


الثغرات أمامهم ومنعهم من تحقيق أهدافهم غير المشروعة عبر الحدود، حيث جاءت الآراء

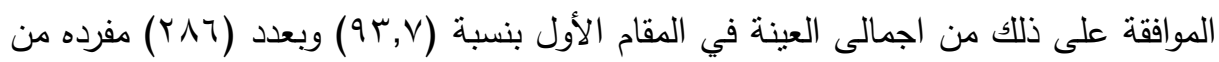

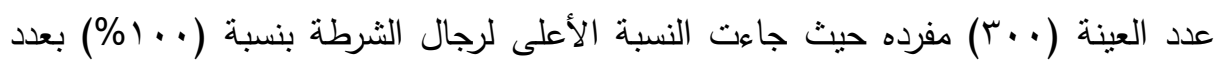

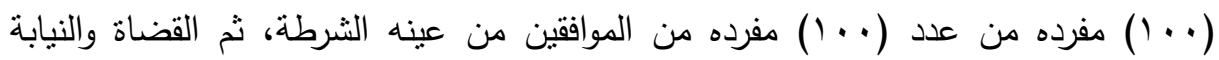

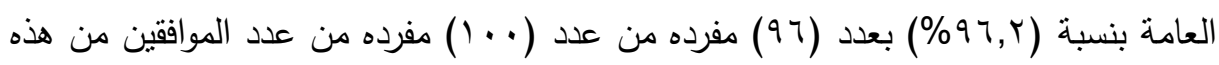

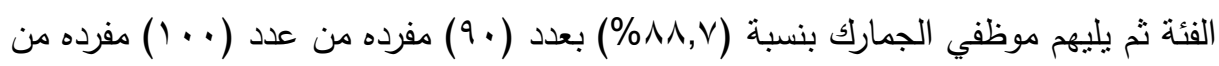

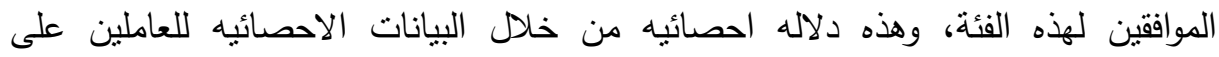

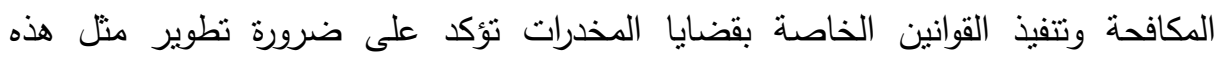
التشريعات والتي تختص بالجمارك وإحكام السيطرة على الواردات والصادرات وتغليظ العقوبات الخاصة بهم. جدول(V): نوزيع عينة الدراسة طبقا لتطوير التشريعات يساعد على استقرار الاقتصاد القومي

\begin{tabular}{|c|c|c|c|c|c|c|c|c|}
\hline \multicolumn{2}{|c|}{ الإجمالي } & \multicolumn{2}{|c|}{ رجال الشرطة } & \multicolumn{2}{|c|}{ موظفي الجمارك } & \multicolumn{2}{|c|}{ قضاة ونيابة } & \multirow{2}{*}{ لاستجابة } \\
\hline$\%$ & ك & $\%$ & ك & ك5 & ك5 & $\%$ & ك & \\
\hline 97,1 & rq. & $97, r$ & 97 & $9 \wedge, 1$ & $9 \wedge$ & $97, r$ & 97 & موافق \\
\hline 1,9 & 7 & 1,9 & $r$ & $\cdot, \cdot$ & . & $r, \Lambda$ & $\varepsilon$ & غير موافق \\
\hline $1, r$ & $\varepsilon$ & 1,9 & r & 1,9 & $r$ & $\cdot, \cdot$ & . & محايد \\
\hline $1 \ldots$ & $\mu \ldots$ & $1 \ldots$ & $1 \ldots$ & $1 \ldots$ & $1 \ldots$ & $1 \ldots$ & $1 \ldots$ & الإجمالي \\
\hline
\end{tabular}

يوضح الجدول رقم (V) والمتعلق بتطوير التشريعات يساعد على استقرار الاقتصاد

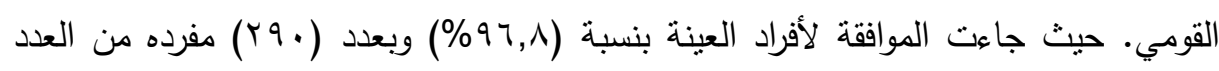
ككل للعينة البالغة (. . r) مفرده حيث جاءت الموافقة بنسبه عاليه. ثم جاءت عدم الموافقة بنسبه ضعيفة بلغت (9,1\%) بعدد (7) مفرده من اجمالى العينة ككل. ثم الآراء المحايدة

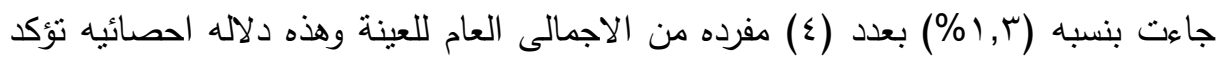

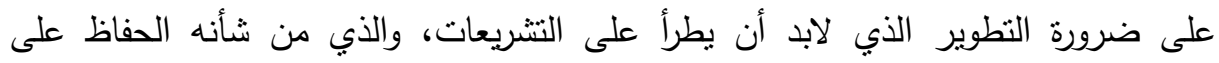
الاستقرار بشكل عام على الاقتصاد القومي.

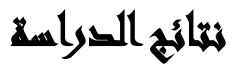

$$
\text { من هنا توصلت الدراسة لعده نتائج هامة هي: }
$$


- أن هناك اتفاق من أفراد العينة بلغت نسبته r, بو\% بوجود علاقة بين الجريمة المنظمة والاتجار غير المشروع بالمخدرات. وهذه النتيجه تتفق مع دراسه اكساكال برباريز عام

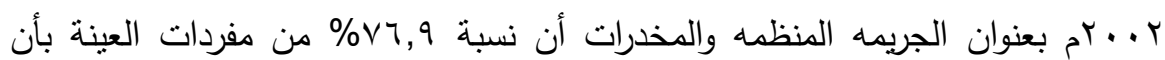

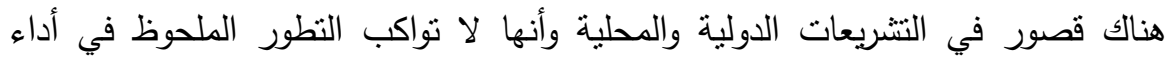
الجماعات القائمة على الجريمة المنظمة. وتتفق هذه النتيجه مع دراسة اليزا نويل عام

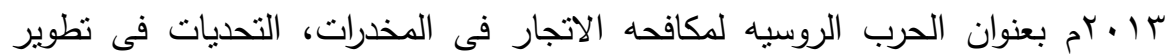

$$
\text { القانون وقدرات الانفاذ. }
$$

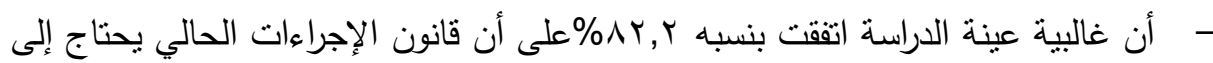
تطوير ليحقق السرعة في البت في القضايا ويحقق الردع للقائمين على الجريمة المنظمة الإنه

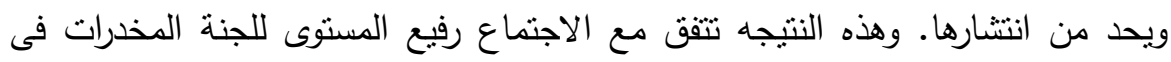

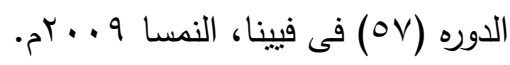

- أن هناك اتفاق بنسبه ^, ب9\% من عينة الدراسة بأن قانون الجمارك يحتاج إلى تطوير ليواكب التطور في الجريمة المنظمة والتجارة الحرة التي هي من أسباب تفاقم هذه الجريمة.

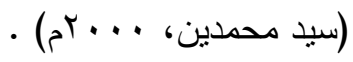

- كما نوصلت الدراسة إلى أن نطوير التشريعات يؤدي إلى استقرار الاقتصاد القومي في المجتمع وأثنتت الدلالة الإحصائية صحة ذلك بنسبه 97,9\% من إجمالي عينة الدراسة.

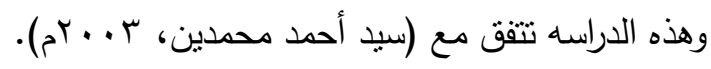

\section{تموسيايت التراسلا}

ا ـ ضرورة التذخل التشريعي لإجراء التعديلات اللازمة في قانون المخدرات رقم بr بالسنة 1919 لمواكبة النطور في الجريمة المنظمة والاتجار غير المشروع بالمخدرات ومتابعة المستجدات أول بأول ووضع القوانين اللازمة لها وتطوير كافة القوانين الخاصة مثل قانون الجمارك وقانون هيئة الاستثمار وقانون الصيادلة مع تفعيل قانون غسل الأموال وإزالة المعوقات التي تواجهه وكذا تطوير قانون الإجراءات الجنائية لسرعة البت في القضايا وتلافى القصور الذي يؤدي إلى الحفظ والبراءة.

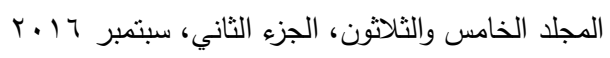


r. إنثاء جهاز إحصائي لمتابعة نشاط المخدرات في مصر وحصر تداول جميع العقاقير والجواهر المخدرة وأعداد المتعاطين فعلياً للوقوف على طبيعة المشكلة لوضع الحلول المناسبة لها تشريعياً وتتفيذياً.

r. تدريب وتوعية القائمين على إنفاذ القانون بكيفية التطبيق السليم للقانون لتجنب أحكام

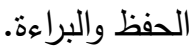

ع. التعاون الدولي وإلزام الدول الأعضاء في الاتفاقية الدولية بتتفيذ موادها على الواقع، مع تعزيز التعاون الدولي في كافة مجالات المكافحة، وتفعيل المؤتمرات الدولية وخاصة دول الجوار، للوقوف على طبيعة المشكلة محاولة لوضع تتريعات متقاربة خاصة مع الدول

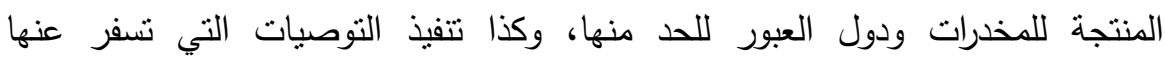
المؤتمرات والندوات.

๑. إنشاء محاكم مختصة للمخدرات، أو دوائر خاصة بمحاكم الجنايات لتداول قضايا المخدرات لتحقيق السرعة في البت فيها، لتحقيق الردع الكافي للقائعين على الجريمة

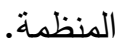

\section{المرالية}

جمال توفيق() r ا •r: الجريمة المنظمة وآليات مكافحتها، في ضوء المواثيق والاتفاقيات

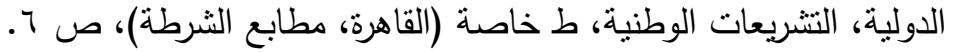

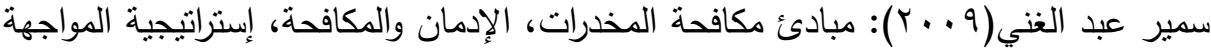

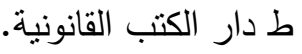

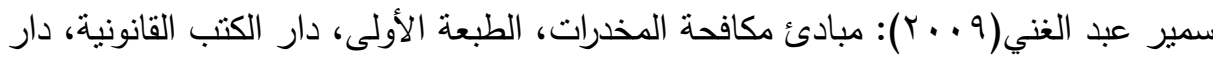

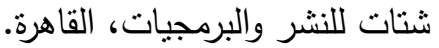

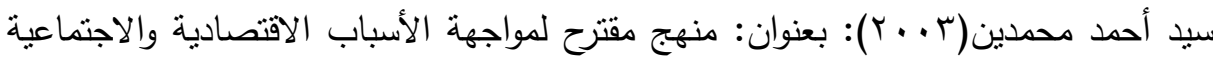

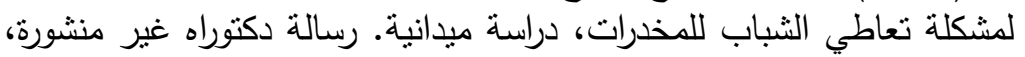

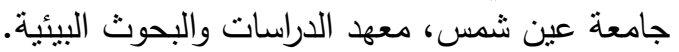
صلاح الدين عامر (990 190): مقدمة لدراسة القانون الدولي العام، دار النهضة العنة العربية، القاهرة،

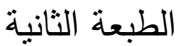




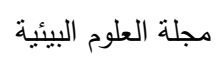

علاء الدين محمد أحمد شحاته(999 (1): الإستراتيجية الوطنية للتعاون الدولي في مجال مكافحة المخدرات، دراسة تطبيقية مقارنة. رسالة دكتوراة، كلية الدراسات العاتية العليا،

$$
\text { القاهرة }
$$

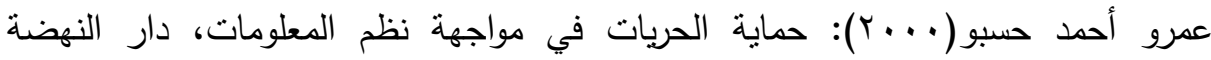

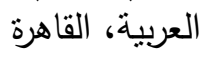

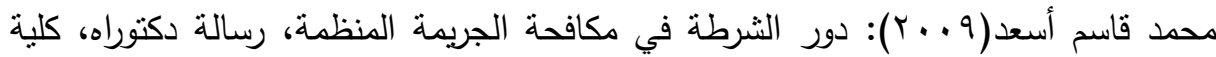

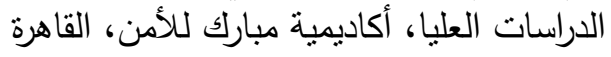

Barrel، Frank (1999): Measuring performance in the organized rime Drug Enforcement task force program. University of Southern California, pro Quest UMI Dissertations publishing. 9987561.

Brownlie (IAN) (1998): Principles of public international law, Fifth Edition clarendan press, Oxford‘, pp. $31-56$

Key, Wei Zhen (2008): Xiamen University (peoples republic of China), An initial Theory of status Crime in the law of great Britain and American and its introduction to China, Pro Quest, UMI, Dissertations publishing H 361799.

Rayn, Kemeth James (2006): Criminal intelligence in the European, union : Evaluating the process efficiencies of cooperation and Coordination, Washington University, pro Quest, UMI Dissertations publishing, 3223460 .

Sharer (I - A) (1994): Statrkes international law Butter wartls London, P.28. 
السيد عيد نايل وآخرون

\title{
A PROPOSED FRAMEWORK FOR THE
} DEVELOPMENT OF LEGISLATION ON

\section{ORGANIZED CRIME AND DRUGS AND ITS}

\section{IMPLICATIONS FOR THE EGYPTIAN SOCIETY}

Nail, E. E. ${ }^{(1)}$; Abd El-bast, F. W. ${ }^{(2)}$ and Abd El-Aziz, M. A. 1) Faculty of Law, Ain Shams University 2) Faculty of Commerce, Ain Shams University

\begin{abstract}
Organized crime and illicit drug trafficking have become a direct threat to the state system. They have weakened and destroyed economic and social institutions. Political and economic changes have contributed to the increase in transnational criminal organizations, especially in the context of economic globalization and great revolution in communications and transportation as well as practicing organized crime. Hence, the term transnational organized crime has been launched and has led to emergence of serious criminal organizations at the international level which rely on the system and strategy of alliances to dominate countries, making it one of the biggest challenges, whether developed or developing.

The aim of the study is to develop legislation related to organized crime and narcotics to limit its impact on the Egyptian society, by exposing the nature of the drug problem, defining the concept of legislation and organizing crime, identifying shortages in order to find out the most important modifications that can be added and identifying scientific vision round most important rules of modification in order to cut the spread of drugs, and their implications.

The study focused on subjects work at drugs' control. It consists of three hundred individuals divided as follows: (100) one hundred members of the judiciary and the Public Prosecution, and (100) one hundred police officers involved in law enforcement and combating

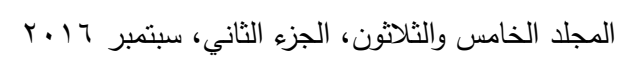


organized crime and drugs, and (100) one hundred members of customs and borders areas as in ports and airports. The study is based on the descriptive approach that is considered as one of the most appropriate scientific curricula for the nature of the study, its objectives and its inquiries. The study used social survey for the sample whom concerned with applying and enforcing the law through questionnaires and codified interviews, in order to obtain data that can be analyzed, interpreted and distributed to answer the questions of the study and achieve its objectives. 